\title{
Lung Ultrasound Combined With Procalcitonin for a Diagnosis of Ventilator-Associated Pneumonia
}

\author{
Juandi Zhou, Jia Song, Shijin Gong, Weihang Hu, Minjia Wang, Aibing Xiao, Cong Zhang, \\ and Zhouzhou Dong
}

\begin{abstract}
BACKGROUND: Lung ultrasound is a valuable imaging tool in the diagnosis of communityacquired pneumonia. However, its diagnostic accuracy in ventilator-associated pneumonia (VAP) has not been fully investigated. The aim of this study was to evaluate the diagnostic performance of the combination of a lung ultrasound with procalcitonin (PCT) in mechanically ventilated subjects with symptoms suggestive of pneumonia. METHODS: A prospective study of 124 subjects with suspected VAP in 2 multidisciplinary ICUs was conducted between December 2016 and October 2017. Lower respiratory tract specimens were collected from all the subjects at enrollment and on the following $3 \mathrm{~d}$. PCT assays were performed within $1 \mathrm{~h}$ of enrollment. Lung ultrasound and then computed tomography of the chest were performed within $24 \mathrm{~h}$ to detect lung consolidations. The subjects were divided into VAP and non-VAP groups according to the results of a computed tomography of the chest and semi-quantitative culture of the lower respiratory tract sample. RESULTS: A total of 124 subjects were included (48 in the VAP group and 76 in the non-VAP group). A positive lung ultrasound result combined with $P C T$ of $\geq 0.25 \mathrm{ng} / \mathrm{mL}$ diagnosed VAP, with a sensitivity and specificity of $\mathbf{8 1 . 3}$ and $\mathbf{8 5 . 5 \%}$, respectively. The area under the receiver operating characteristic curve was significantly higher for lung ultrasound combined with PCT than for a white blood cell count, PCT, C-reactive protein, or Clinical Pulmonary Infection Score alone. CONCLUSIONS: A combination of lung ultrasound and PCT was accurate in the diagnosis of VAP. Lung ultrasound is a useful lung-imaging tool to assist VAP diagnosis. Key words: pneumonia; ventilator-associated; lung ultrasound; procalcitonin; diagnosis. [Respir Care 2019;64(5):519-527. (C) 2019 Daedalus Enterprises]
\end{abstract}

\section{Introduction}

Ventilator-associated pneumonia (VAP) is the most common nosocomial infection in the ICU and affects one third

\footnotetext{
Dr Zhou is affiliated with the Department of General Surgery, Zhejiang Hospital, Hangzhou, China. Drs Song, Gong, Hu, and Wang are affiliated with the Department of Critical Care Medicine, Zhejiang Hospital, Hangzhou, China. Dr Xiao is affiliated with the Department of Critical Care Medicine, Taizhou Municipal Hospital, Taizhou, China. Dr Zhang is affiliated with the Zhejiang Chinese Medical University, Hangzhou, China. Dr Dong is affiliated with the Department of Critical Care Medicine, Ningbo Medical Center Lihuili Eastern Hospital, Ningbo, China.
}

Drs Zhou and Song contributed equally as first authors.

This work was supported by the scientific research fund of the National Health and Family Planning Commission of PRC-Major science (WKJZJ-1601), and Zhejiang medical and health science and technology plan project (2017KY182). of patients who require mechanical ventilation during a noninfectious admission. ${ }^{1}$ VAP is associated with longer ICU length of stays, prolonged mechanical ventilation, and increased use of antimicrobials, health-care costs, and mortality. ${ }^{2-4}$ VAP has been reported to increase the mortality of the underlying disease by $\sim 30 \% . .^{5}$ An early diagnosis of VAP is crucial for prompt initiation of appropriate

\footnotetext{
The authors have disclosed no conflicts of interest.

Supplementary material related to this paper is available at http:// www.rcjournal.com.

Correspondence: Jia Song MD, Department of Critical Care Medicine, Zhejiang Hospital, 12 Lingyin Road, Hangzhou, Zhejiang 310013, China. E-mail: songjia9a@163.com.
}

DOI: $10.4187 /$ respcare.06377 
treatment. Currently, VAP is diagnosed based on a combination of clinical, radiologic, and microbiologic criteria.

Radiologic findings are intrinsic to most diagnostic VAP algorithms. ${ }^{6}$ Pulmonary imaging for a diagnosis of VAP lung consolidation still relies on chest radiography and computed tomography (CT) of the chest. ${ }^{7}$ However, several studies indicate that chest $\mathrm{x}$-ray is unreliable for VAP diagnosis in patients who are critically ill,,${ }^{8,9}$ and, thus, its utility in the ICU is limited. Although CTs allow visualization of much smaller pulmonary abnormalities than chest radiography, CT cannot be routinely performed in patients who are critically ill because of the cost, radiation exposure, and risk of transportation..$^{10}$ In this context, there is a need for a radiation-free, noninvasive, and easily repeatable bedside tool for detection of lung consolidation in patients who require mechanical ventilation. More recently, advances in ultrasound technology and its widespread use in patients who are critically ill have recommended lung ultrasound as a promising tool for assessing lung status in patients who are critically ill and on mechanical ventilation. A lung ultrasound was reported to have a high accuracy in many pathological lung conditions, such as consolidation, pleural effusion, interstitial syndrome, and pneumothorax. ${ }^{11-13}$

Procalcitonin (PCT) is a biomarker closely related to bacterial infection and has been used in the diagnosis of community-acquired infections, particularly lower respiratory tract infections. ${ }^{14}$ Moreover, studies reported that a PCT-guided strategy could shorten antimicrobial-treatment duration and reduce antibiotic prescriptions for patients with community-acquired lower respiratory tract infections. ${ }^{15,16}$ Despite its unquestionable role in communityacquired pneumonia diagnosis, the PCT level alone does not seem to be a good diagnostic biomarker for VAP. Gibot et $\mathrm{al}^{17}$ found no difference in serum PCT levels between subjects with and without VAP. However, a score that combined PCT and lung ultrasound was recently reported to outperform the Clinical Pulmonary Infection Score (CPIS) in a VAP diagnosis. ${ }^{18}$ Therefore, we carried out this prospective, observational study in 2 centers to confirm the diagnostic performance of the combination of lung ultrasound with PCT in subjects with suspected VAP. We hypothesized that the diagnostic performance of the combination of lung ultrasound and PCT would be better than other biomarkers.

\section{Methods}

The study was approved by the Zhejiang Hospital Ethics Committee (201625K), and written informed consent was obtained from each subject's next of kin. We prospectively included 124 consecutive subjects with suspected VAP in ICUs at the Zhejiang Hospital and the Taizhou Municipal Hospital between December 2016 and October

\section{QUICK LOOK}

\section{Current knowledge}

Ventilator-associated pneumonia (VAP) is the most frequent ICU-acquired infection that is independently associated with mortality. Diagnosing VAP remains a challenge for clinicians.

\section{What this paper contributes to our knowledge}

In mechanically ventilated subjects with signs and symptoms of pneumonia, lung ultrasound patterns of lung consolidation combined with procalcitonin of $\geq 0.25 \mathrm{ng} / \mathrm{mL}$ showed a better diagnostic performance than did a lung ultrasound, procalcitonin, Clinical Pulmonary Infection Score, and other inflammatory biomarkers alone for VAP diagnosis. A lung ultrasound was a useful tool to assist in VAP diagnosis.

2017. Inclusion criteria were as follows: (1) duration of mechanical ventilation of $\geq 48 \mathrm{~h}$; (2) age $\geq 18 \mathrm{y}$; and (3) clinical suspicion of VAP based on two or more of the following criteria: body temperature of $\geq 38.0^{\circ} \mathrm{C}$ or $<36.0^{\circ} \mathrm{C}$, white blood cell count $\geq 10,000$ or $\leq 4,000$ cells $/ \mathrm{mm}^{3}$, purulent tracheal secretions, and $\mathrm{P}_{\mathrm{aO}} / \mathrm{F}_{\mathrm{IO}_{2}}<300 \mathrm{mmHg}$. Exclusion criteria were ongoing pneumonia, subcutaneous emphysema, thoracic dressings, or pregnancy.

The subjects were enrolled when VAP was suspected. Lower respiratory tract specimens were collected by deep bronchial suctioning or bronchoscopic lavage at inclusion and, thereafter, daily for $3 \mathrm{~d}$. Blood samples were collected for PCT testing within $1 \mathrm{~h}$ after inclusion. We considered 2 PCT cutoffs, of 0.25 and $0.5 \mathrm{ng} / \mathrm{mL}$, based on previous studies. ${ }^{14-16}$ The cutoff of $\leq 0.25 \mathrm{ng} / \mathrm{mL}$ PCT was used to rule out bacterial pneumonia in the subjects with suspected respiratory tract infections, and a PCT level of $\geq 0.5 \mathrm{ng} / \mathrm{mL}$ was used to indicate bacterial pneumonia and to recommend antibiotic therapy.

A CT of the chest was performed by using a Somatom Sensation (Siemens, Erlangen, Germany) and a GE Lightspeed 64 (GE, Boston, Massachusetts) within $24 \mathrm{~h}$ of inclusion. Two individual radiologists, unaware of the lung ultrasound findings, studied the images together, and diagnostic reporting was determined by consensus. For each subject, VAP was diagnosed according to 2 criteria: new or progressive infiltrates on a CT of the chest, and a positive semi-quantitative bacterial culture of lower respiratory tract sample. The semi-quantitative culture was determined by four-quadrant streak plate method and classified as follows: $+=$ rare growth; $++=$ light growth; $+++=$ moderate growth; $++++=$ heavy growth. $\mathrm{A}$ positive semi-quantitative culture was defined as +++ or ++++ . 
A lung ultrasound was performed before the CT of the chest to minimize the bias induced by subjective judgment. The subjects were examined while they were in the supine and lateral positions. The following ultrasound machines were used: SonoSite M-Turbo (Fujifilm, Tokyo, Japan) and X-Porte (Fujifilm), with a 3.5-10usb MHz convex array probe. A longitudinal scan was taken in 6 areas for each hemithorax (anterior, lateral, posterior regions by using anterior and posterior axillary lines as landmarks, and each region was divided into upper and lower halves by using the third intercostal spaces as landmarks). For each region of interest, the worst ultrasound abnormality detected was considered to characterize the region examined.

Four lung ultrasound patterns were defined as positive results (see the supplementary materials at http://www. rcjournal.com): (1) small subpleural consolidations: subpleural blurred, irregular margins echo-poor regions, diameter $>0.5 \mathrm{~cm}$, with or without B lines; (2) lobarhemilobar consolidation, defined by a tissue-like echotexture similar to that observed in liver or spleen parenchyma on ultrasound; (3) dynamic air bronchogram, defined as punctiform or linear hyperechoic artifacts within lobar-hemilobar consolidations and the hyperechoic images moving synchronously with inspiration; and (4) static air bronchogram: hyperechoic artifacts within lobarhemilobar consolidations but not moving with inspiration. The investigators were 4 intensive care physicians (Song, $\mathrm{Hu}$, Wang, Xiao) who had received standard training in point-of-care ultrasound and with at least $3 \mathrm{y}$ of experience with lung ultrasound.

For each subject, the following data were collected: age, sex, APACHE II (Acute Physiology and Chronic Health Evaluation II) score, and where the patient was transferred from. The clinical and laboratory data included the following: body temperature, white blood cell count, plasma concentration of C-reactive protein, $\mathrm{PCT}, \mathrm{P}_{\mathrm{aO}_{2}} / \mathrm{F}_{\mathrm{IO}_{2}}$, quality of bronchial secretions, and the results of lower respiratory tract specimen culture. CPIS, duration of mechanical ventilation, ICU length of stay, ICU mortality, and results of the lung ultrasound examination were also recorded.

\section{Statistics}

Statistical analysis was performed by using SPSS 20.0 software (IBM Corporation, Armonk, New York). All data are expressed as mean $\pm \mathrm{SD}$ when normally distributed or as median (25-75\% interquartile range) when non-normally distributed. The normality of data distribution was assessed by using the Kolmogorov-Smirnov test. The Student $t$ test was used for comparison of normally distributed continuous data, and the Mann-Whitney U test was used for comparison of skewed continuous data. The chi-square test or the Fisher exact test was used to compare categorical variables. A 2 -tailed $P<.05$ was considered to indicate statistical significance.

The diagnostic performance of a lung ultrasound, CPIS, PCT, and the combination of lung ultrasound and PCT were assessed by sensitivity, specificity, positive predictive value, negative predictive value, and likelihood ratios. The McNemar test were used to evaluate the significance of differences in the sensitivity and specificity of lung ultrasound, CPIS, PCT, and the combination of lung ultrasound and PCT. Receiver operating characteristic curves were constructed to evaluate the ability of the white blood cell count, PCT, C-reactive protein, CPIS, and combination of lung ultrasound and PCT to predict VAP. The areas under the receiver operating characteristic curves were compared by using the Hanley-McNeil test. ${ }^{19}$

\section{Results}

A total of 150 patients fulfilled inclusion criteria during the study period. Eighteen patients could not undergo CT examination within $24 \mathrm{~h}$ after enrollment due to an unstable clinical condition. Six patients did not get the PCT test, and 2 patients refused to participate in the study. As a result, a total of 124 subjects were included in the final analysis (Fig. 1). The subjects were divided into VAP $(n=48)$ and non-VAP groups $(n=76)$ according to CT results and semi-quantitative cultures of respiratory tract secretions. Baseline and clinical characteristics are shown in Table 1. More postoperative subjects (postoperative subjects percentage of 34.2 vs $16.7 \% ; P=.033$ ) were categorized into the non-VAP group, and their PCT levels (median 0.3 vs $1.07 \mathrm{ng} / \mathrm{mL}, P=.001$ ) and CPIS (median 5.6 vs $6.9, P=.002$ ) were significantly lower than in the VAP group. Furthermore, more subjects in the VAP group had purulent airway secretions (subjects have purulent airway secretions percentage of 77.1 vs $43.4 \%, P<.001$ ) and strongly positive semi-quantitative cultures (strongly positive semi-quantitative cultures percentage of 62.5 vs $13.2 \%, P<.001)$. Both the duration of mechanical ventilation (median $8.5 \mathrm{vs} 12 \mathrm{~d}, P=.003$ ) and ICU length of stay (median 11.5 vs $17 \mathrm{~d}, P<.001$ ) were significantly longer in the VAP group than in the non-VAP group. The ICU mortality (the ICU mortality percentage of 28.9 vs $41.7 \%, P=.15$ ) did not differ significantly between the 2 groups.

Performance of a lung ultrasound, PCT, CPIS, and lung ultrasound combined with PCT in diagnosing VAP are presented in Table 2. Forty four of 72 subjects (61.1\%) with positive lung ultrasound results were diagnosed with VAP. False-negative results were found in 4 subjects (3.2\%), with a sensitivity of $91.7 \%$ (95\% CI 79.1-97.3\%), a negative predictive value of $92.3 \%$ (95\% CI 80.6-97.5\%), and a negative likelihood ratio of 0.13 (95\% CI $0.05-$ 


\section{LUNG UltRASOUND FOR VAP DiAgNOSIS}

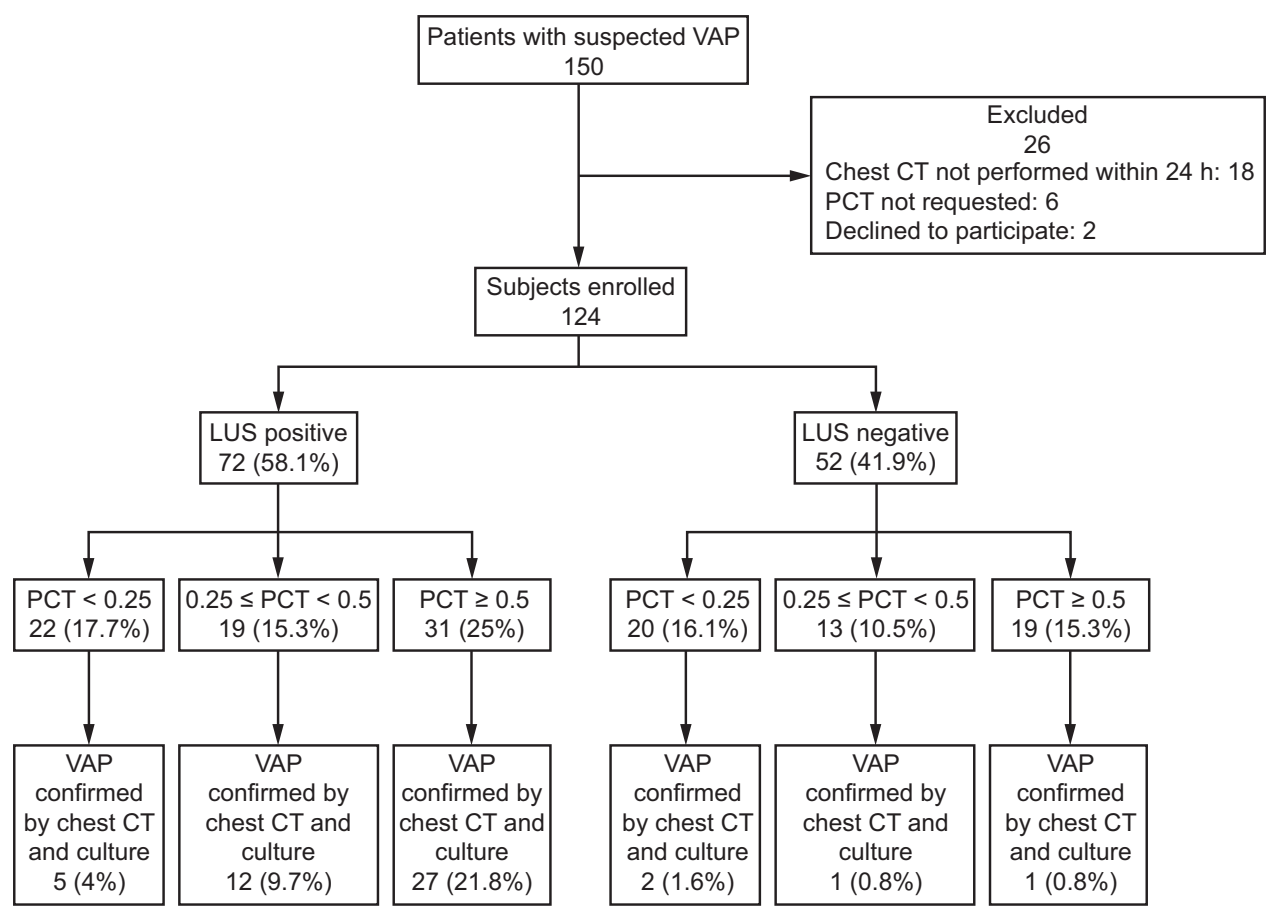

Fig. 1. Flow chart. VAP $=$ ventilator-associated pneumonia, CT $=$ computed tomography, LUS $=$ lung ultrasound, PCT $=$ procalcitonin.

Table 1. Clinical Characteristics of the Study Population

\begin{tabular}{|c|c|c|c|}
\hline Characteristic & non-VAP Group $(n=76)$ & VAP Group $(n=48)$ & $P$ \\
\hline Male/female, $n$ & $45 / 31$ & $30 / 18$ & \\
\hline Age, mean \pm SD y & $69.3 \pm 13.0$ & $68.7 \pm 11.3$ & .76 \\
\hline APACHE II score, mean \pm SD & $17.4 \pm 3.9$ & $18.2 \pm 3.1$ & .22 \\
\hline \multicolumn{4}{|l|}{ Source of ICU admission, $n(\%)$} \\
\hline Emergency department & $20(26.3)$ & $14(29.2)$ & .73 \\
\hline Medical & $30(39.5)$ & $26(54.2)$ & .11 \\
\hline After surgery & $26(34.2)$ & $8(16.7)$ & .033 \\
\hline Body temperature, mean $\pm \mathrm{SD}{ }^{\circ} \mathrm{C}$ & $37.8 \pm 0.7$ & $38.1 \pm 0.8$ & .08 \\
\hline White blood cell count, mean $\pm \mathrm{SD} \times 10^{9} / \mathrm{L}$ & $11.8 \pm 4.3$ & $13.2 \pm 4.0$ & .08 \\
\hline C-reactive protein, mean $\pm \mathrm{SD} \mathrm{mg} / \mathrm{L}$ & $62.1 \pm 46.3$ & $78.0 \pm 47.1$ & .07 \\
\hline Procalcitonin, median (IQR) $\mathrm{ng} / \mathrm{mL}$ & $0.30(0.19-1.95)$ & $1.07(0.39-2.61)$ & .001 \\
\hline $\mathrm{P}_{\mathrm{aO}_{2}} / \mathrm{F}_{\mathrm{IO}_{2}}$, mean $\pm \mathrm{SD}$ & $251.9 \pm 48.1$ & $232.7 \pm 61.1$ & .053 \\
\hline Purulent endotracheal aspirations, $n(\%)$ & $33(43.4)$ & $37(77.1)$ & $<.001$ \\
\hline \multicolumn{4}{|l|}{ Semi-quantitative bacterial culture, $n(\%)$} \\
\hline+ & $22(28.9)$ & & \\
\hline++ & $27(35.5)$ & & \\
\hline+++ & $17(22.4)$ & $18(37.5)$ & .07 \\
\hline++++ & $10(13.2)$ & $30(62.5)$ & $<.001$ \\
\hline Clinical pulmonary infection score, mean $\pm \mathrm{SD}$ & $5.6 \pm 2.3$ & $6.9 \pm 2.3$ & .002 \\
\hline \multicolumn{4}{|l|}{ Prognosis, median (IQR) } \\
\hline Mechanical ventilation, $\mathrm{d}$ & $8.5(6.0-14.0)$ & $12.0(8.0-20.0)$ & .003 \\
\hline ICU length of stay, $d$ & $11.5(8.0-19.5)$ & $17.0(12.0-26.8)$ & $<.001$ \\
\hline ICU mortality, $n(\%)$ & $22(28.9)$ & $20(41.7)$ & .15 \\
\hline $\begin{array}{l}\text { VAP }=\text { ventilator-associated pneumonia } \\
\text { APACHE II = Acute Physiology and Chronic Health Evaluation } \\
\text { IQR = interquartile range }\end{array}$ & & & \\
\hline
\end{tabular}




\section{LUNG UltRASOUND FOR VAP DiAgNOSIS}

Table 2. Diagnostic Performance of Lung Ultrasound, Procalcitonin, CPIS, and Lung Ultrasound Combined With Procalcitonin for a VAP Diagnosis

\begin{tabular}{lccccccc}
\hline \hline Diagnostic Performance & $\begin{array}{c}\text { Subjects, } \\
n\end{array}$ & $\begin{array}{c}\text { Sensitivity, \% } \\
(95 \% \mathrm{CI})\end{array}$ & $\begin{array}{c}\text { Specificity, \% } \\
(95 \% \mathrm{CI})\end{array}$ & $\begin{array}{c}\mathrm{PPV}, \% \\
(95 \% \mathrm{CI})\end{array}$ & $\begin{array}{c}\text { NPV, \% } \\
(95 \% \mathrm{CI})\end{array}$ & $\begin{array}{c}\text { +LR, \% } \\
(95 \% \mathrm{CI})\end{array}$ & $\begin{array}{c}-\mathrm{LR}, \% \\
(95 \% \mathrm{CI})\end{array}$ \\
\hline $\begin{array}{l}\text { Positive lung ultrasound } \\
\text { result }\end{array}$ & 72 & $91.7(79.1-97.3)$ & $63.2(51.3-73.7)$ & $61.1(48.9-72.2)$ & $92.3(80.6-97.5)$ & $2.49(1.83-3.38)$ & $0.13(0.05-0.34)$ \\
$\mathrm{PCT} \geq 0.25 \mathrm{ng} / \mathrm{mL}$ & 82 & $85.4(71.6-93.5)$ & $46.1(34.7-57.8)$ & $50.0(38.8-61.2)$ & $83.3(68.0-92.5)$ & $1.58(1.25-2.01)$ & $0.32(0.15-0.65)$ \\
$\mathrm{PCT} \geq 0.5 \mathrm{ng} / \mathrm{mL}$ & 50 & $58.3(43.3-72.1)$ & $71.1(59.4-80.6)$ & $56.0(41.4-69.7)$ & $73.0(61.2-82.3)$ & $2.02(1.32-3.08)$ & $0.59(0.42-0.83)$ \\
CPIS $\geq 6$ & 66 & $70.8(55.7-82.6)$ & $57.9(46.0-69.0)$ & $51.5(39.0-63.9)$ & $75.9(62.5-85.7)$ & $1.68(1.22-2.32)$ & $0.50(0.32-0.80)$ \\
Positive lung ultrasound & 50 & $81.3(66.9-90.6)$ & $85.5(75.2-92.2)$ & $78.0(63.7-88.0)$ & $87.8(77.7-93.9)$ & $5.61(3.20-9.86)$ & $0.22(0.12-0.40)$
\end{tabular}

result and $\mathrm{PCT} \geq$

$0.25 \mathrm{ng} / \mathrm{mL}$

CPIS = Clinical Pulmonary Infection Score

VAP $=$ Ventilator-associated pneumonia. Ventilator-associated pneumonia

PPV $=$ positive predictive value

$\mathrm{NPV}=$ negative predictive value

$+\mathrm{LR}=$ positive likelihood ratio

$-\mathrm{LR}=$ negative likelihood ratio

$\mathrm{PCT}=$ procalcitonin

$0.34)$. Sensitivity and the specificity of PCT $\geq 0.25 \mathrm{ng} / \mathrm{mL}$ were $85.4 \%$ (95\% CI $71.6-93.5 \%$ ) and $46.1 \%$ (95\% CI $34.7-57.8 \%$ ), respectively, whereas sensitivity and the specificity of PCT $\geq 0.5 \mathrm{ng} / \mathrm{mL}$ were $58.3 \%(95 \%$ CI $43.3-72.1 \%$ ) and $71.1 \%$ (95\% CI 59.4-80.6\%), respectively.

CPIS $\geq 6$ had a sensitivity of $70.8 \%$ (95\% CI $55.7-$ $82.6 \%)$ and a specificity of $57.9 \%$ (95\% CI $46.0-69.0 \%)$. Thirty nine of 50 subjects $(78 \%)$ with a positive lung ultrasound result and PCT $\geq 0.25 \mathrm{ng} / \mathrm{mL}$ had a final diagnosis of VAP, false-negative results were 9 (7.3\%). The sensitivity, negative predictive value, and negative likelihood ratio were $81.3 \%$ (95\% CI 66.9-90.6\%), 87.8\% (95\% CI 77.7-93.9\%), and 0.22 (95\% CI 0.12-0.40), respectively. In 74 subjects $(59.7 \%)$, a lung ultrasound was negative and/or PCT $<0.25 \mathrm{ng} / \mathrm{mL}$. False-positive results were found in 11 subjects (8.9\%). The specificity, positive predictive value, and positive likelihood ratio were $85.5 \%$ (95\% CI 75.2-92.2\%), 78.0\% (95\% CI 63.7-88.0\%), and 5.61 (95\% CI 3.20-9.86), respectively.

A lung ultrasound diagnosed VAP more sensitively than $\operatorname{did}$ PCT $\geq 0.5 \mathrm{ng} / \mathrm{mL}\left(\chi^{2}=12.5, P<.001\right)$ and CPIS $\left(\chi^{2}=5.79, P=.02\right)$. However, it was comparable in subjects with PCT $\geq 0.25 \mathrm{ng} / \mathrm{mL}\left(\chi^{2}=0.57, P=.45\right)$ and those with positive lung ultrasound result and PCT $\geq 0.25$ $\mathrm{ng} / \mathrm{mL}\left(\chi^{2}=3.2, P=.07\right)$. The specificity of a positive lung ultrasound result combined with $\mathrm{PCT} \geq 0.25 \mathrm{ng} / \mathrm{mL}$ was significantly higher than a lung ultrasound $\left(\chi^{2}=15.06\right.$, $P<.001)$, PCT $\geq 0.5\left(\chi^{2}=4.0, P=.046\right)$, PCT $\geq 0.25$ $\left(\chi^{2}=28.03, P<.001\right)$, and CPIS $\left(\chi^{2}=13.79, P<.001\right)$ alone. Sonographic patterns for lung ultrasound evaluation of the study subjects are described in Table 3.

Areas under the receiver operating characteristic curves of white blood cell count, PCT, C-reactive protein, CPIS,
Table 3. Different Lung Ultrasound Patterns in the Study Subjects

\begin{tabular}{lc}
\hline \hline \multicolumn{1}{c}{ Lung Ultrasound Patterns } & Subjects, $n(\%)$ \\
\hline Small subpleural consolidations & $13(18.1)$ \\
Lobar-hemilobar consolidations & $13(18.1)$ \\
Static air bronchogram & $3(4.2)$ \\
Dynamic air bronchogram & $9(12.5)$ \\
Small subpleural consolidations and & $8(11.1)$ \\
$\quad$ lobar-hemilobar consolidations & $10(13.9)$ \\
Small subpleural consolidations and & \\
$\quad$ static air bronchogram & $16(22.2)$ \\
Small subpleural consolidations and & \\
dynamic air bronchogram & \\
\hline
\end{tabular}

and PCT combined with lung ultrasound were 0.625 (95\% CI 0.525-0.726), 0.674 (95\% CI 0.581-0.768), 0.620 (95\% CI 0.521-0.720), 0.665 (95\% CI 0.567-0.762), and 0.865 (95\% CI $0.794-0.936$ ), respectively (Fig. 2). The area under the receiver operating characteristic curve of PCT combined with lung ultrasound was significantly higher than those of white blood cell count $(P<.001)$, PCT $(P=.001)$, C-reactive protein $(P<.001)$, and CPIS $(P=.001)$.

\section{Discussion}

In the present study, we validated the diagnostic value of a combination of a lung ultrasound and with PCT in the subjects who were on ventilation and with signs and symptoms of VAP. Lung ultrasound patterns of lung consolidation combined with PCT $\geq 0.25 \mathrm{ng} / \mathrm{mL}$ showed better diagnostic performance than a lung ultrasound, PCT, CPIS, and other inflammatory biomarkers alone for VAP diagnosis. The Centers for Disease Control define VAP as a 


\section{LUNG UltRASOUND FOR VAP DiAgNOSIS}

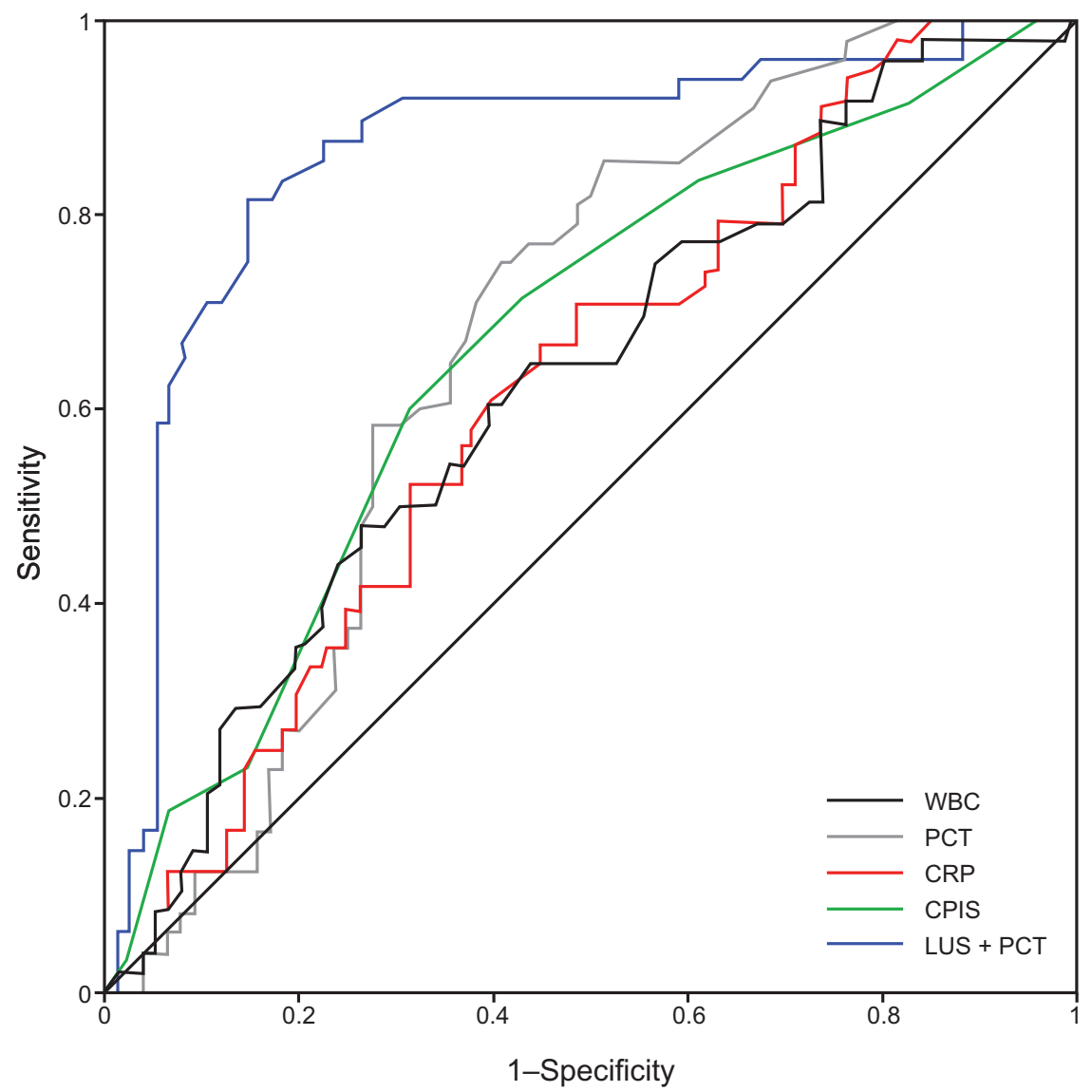

Fig. 2. Receiver operating characteristics curves of white blood cells (WBC), procalcitonin (PCT), C-reactive protein (CRP), Clinical Pulmonary Infection Score (CPIS), and lung ultrasound (LUS) combined with PCT.

pneumonia that arises within the 48-h period of the placement of an artificial airway. ${ }^{20} \mathrm{~A}$ diagnosis of VAP in patients who are critically ill remains challenging, and there is a lack of consensus regarding the diagnostic criteria for VAP. ${ }^{21}$ Traditional diagnostic criteria for VAP are based on medical history, physical examination, and radiographic findings. As an important lung imaging tool, bedside chest $\mathrm{x}$-ray is routinely used for VAP diagnosis. However, it lacks both accuracy and reliability for the diagnosis of pneumonia in the ICU.22 In one report, 38\% of subjects undergoing mechanical ventilation had abnormal chest radiography findings on ICU admission. ${ }^{23}$ In addition, in patients who are bedridden and with suspected pneumonia, a normal chest $\mathrm{x}$-ray cannot rule out the diagnosis. ${ }^{24}$ Another diagnostic tool, the CT of the chest, is considered as the accepted standard for the diagnosis of pneumonia. Therefore, we used a CT of the chest as the accepted standard for the confirmation of VAP. However, we acknowledge that the routine use of CT is limited. In this study, 18 subjects were excluded due to unstable hemodynamics because a CT of the chest could not be performed.

A number of studies reported the value of a lung ultrasound for the diagnosis and management of community- acquired pneumonia, and it seemed to be more accurate than chest radiography. ${ }^{25-27}$ In a prospective, multi-center study designed to define the accuracy of a lung ultrasound in the diagnosis of community-acquired pneumonia, ${ }^{25} \mathrm{a}$ lung ultrasound showed an excellent sensitivity and specificity, of $94 \%$ and $98 \%$, respectively, which was comparable with that of a chest $\mathrm{x}$-ray in 2 planes. Cortellaro et al ${ }^{28}$ found that the lung ultrasound had a sensitivity and specificity of $98 \%$ and $95 \%$, respectively, higher than that of a chest x-ray whose sensitivity and specificity were $67 \%$ and $85 \%$, respectively. In spite of the differences in pathogenesis between community-acquired pneumonia and VAP, both conditions eventually lead to lung consolidation with loss of aeration. ${ }^{29}$ Therefore, they share common lung ultrasound features.

Previous reports show that almost all VAPs cause various degrees of lung consolidation, whereas a lung ultrasound can be sensitive for the detection of these pathological abnormalities, ${ }^{30,31}$ which explains the excellent sensitivity of lung ultrasound in our study. Of the 48 subjects finally diagnosed with VAP, 44 showed signs of lung consolidation in a lung ultrasound, which resulted in a sensitivity of $91.7 \%$ and a negative predictive value of 
92.3\% in the VAP diagnosis. We can argue that a negative result of the lung ultrasound examination may rule out VAP with a sufficient level of certainty. Of note, we also found a lower diagnostic specificity of lung ultrasound alone than in community-acquired pneumonia.

In the ICU, lung consolidations detected by lung ultrasound in patients on ventilation can be caused by numerous factors other than inflammation. ${ }^{32,33}$ Pleural effusion, pulmonary hemorrhage, pulmonary embolism, postobstructive atelectasis, or other pathological abnormalities are also characterized by lung consolidation as detected by a lung ultrasound. The presence of a lung ultrasound cannot be used to accurately differentiate between inflammatory and non-inflammatory lung consolidation. Therefore, lung consolidation in lung ultrasound imaging is not specific for VAP diagnosis. When taking this into consideration, a lung ultrasound combined with other inflammatory biomarkers may exclude consolidations caused by non-inflammatory factors and may be able to improve the specificity of lung ultrasound.

PCT is secreted as part of the systemic inflammatory response to bacterial infections and has been considered to be a valuable biomarker for the diagnosis and follow-up of patients with sepsis and community-acquired pneumonia. ${ }^{34}$ Despite its definitive role in the confirmation of sepsis and community-acquired pneumonia, its usefulness as a diagnostic marker in hospital-acquired infections, particularly those with VAP, remains controversial. ${ }^{35}$ Several studies showed that PCT was a low-sensitivity diagnostic marker for VAP. ${ }^{36,37}$ Similarly, in our study, PCT alone could not diagnose VAP sufficiently accurately, whether using a threshold of 0.25 or $0.5 \mathrm{ng} / \mathrm{mL}$. Efforts have been made to overcome these limitations. For example, Zagli et al ${ }^{18}$ developed a novel score, CEPPIS (chest echography and procalcitonin pulmonary infection score), based on a combination of PCT and lung ultrasound for a VAP diagnosis.

The new proposed score differed from the traditional CPIS in 2 aspects: the white blood cell count was replaced by PCT, and chest x-ray was replaced by a lung ultrasound. The sensitivity of CEPPIS (80.5\%) was reportedly greater than that of CPIS (39.8\%) for a VAP diagnosis, whereas the specificity was comparable (specificity 85.2 vs $83.3 \%$ ). In our study, the specificity of a positive lung ultrasound examination combined with a PCT of $\geq 0.25$ $\mathrm{ng} / \mathrm{mL}$ was $85.5 \%$, which was significantly higher than a lung ultrasound, PCT, and CPIS alone. The combination of positive lung ultrasound and positive PCT results significantly improved the specificity of a lung ultrasound for a VAP diagnosis, which reduced the occurrence of false positives because a positive PCT result can exclude most of the consolidations caused by non-infectious factors.

However, our study showed that, when a lung ultrasound identified a typical consolidation pattern, the sensitivity for a VAP diagnosis was not significantly influenced by the addition of PCT. Based on our results, the combination of a lung ultrasound and PCT had a better diagnosis value than clinically used inflammatory biomarkers or CPIS. Furthermore, a lung ultrasound can track the progression of the pneumonia treated by antibiotics. In the study by Bouhemad et al, ${ }^{33}$ they compared the accuracy of chest $\mathrm{x}$-ray and a lung ultrasound for measuring lung reaeration that resulted from the administration of antibiotics in subjects with VAP. A lung ultrasound seems to be an accurate diagnostic tool for assessing the respiratory effects of antimicrobial therapy in patients with VAP. It allows the early detection of antibiotic-induced lung reaeration or the extension of lung infection in cases of antimicrobial therapy failure.

Several limitations should be acknowledged in the study. First, airway secretion specimens obtained from endotracheal aspiration were at risk of contamination by upper respiratory tract colonization, and the accuracy of semiquantitative culture was inferior to quantitative culture. Bronchoscopic bronchoalveolar lavage or protected specimen brush may be superior, but Bronchoscopy is an invasive technique and requires highly skilled operators. Furthermore, Bronchoscopy is not possible to use in all patients. ${ }^{38}$ In addition, due to logistical reasons, many institutions in China cannot carry out quantitative culture of bacteria. Therefore, semi-quantitative culture of endotracheal aspiration is more applicable in clinical practices. Second, a lung ultrasound is just an alternative to other lung-imaging techniques, it should always be combined with the patient's history, physical examination, and laboratory analysis. Third, a lung ultrasound is highly operator dependent, and the accuracy of the results depend on the skills of the operator. In our study, a lung ultrasound was performed by experienced physicians, all of whom received standard training in point-of-care ultrasound. Fourth, some conditions may exclude an examination with a lung ultrasound, for example, patients who are obese, those who had thoracic surgery, and those with severe chest trauma. Fifth, our study was a pilot, exploratory study, and more clinical studies will be needed to confirm the diagnostic accuracy of a lung ultrasound in VAP.

\section{Conclusions}

The combination of a lung ultrasound and PCT showed a better diagnostic performance than a lung ultrasound, PCT, CPIS, and other inflammatory biomarkers alone for a VAP diagnosis in the subjects who were on ventilation and with signs and symptoms of pneumonia. As a useful lung imaging tool in the diagnosis of VAP, examination with a lung ultrasound should be encouraged, especially in the ICU. 


\section{LUNG UltRASOUND FOR VAP DiAgNOSIS}

\section{REFERENCES}

1. Magill SS, Klompas M, Balk R, Burns SM, Deutschman CS, Diekema D, et al. Developing a new, national approach to surveillance for ventilator-associated events. Am J Crit Care 2013; 22(6):469-473.

2. Kollef MH, Hamilton CW, Ernst FR. Economic impact of ventilatorassociated pneumonia in a large matched cohort. Infect Control Hosp Epidemiol 2012;33(3):250-256.

3. Melsen WG, Rovers MM, Groenwold RH, Bergmans DC, Camus C, Bauer TT, et al. Attributable mortality of ventilator-associated pneumonia: a meta-analysis of individual patient data from randomised prevention studies. Lancet Infect Dis 2013;13(8):665-671.

4. Melsen WG, Rovers MM, Koeman M, Bonten MJ. Estimating the attributable mortality of ventilator-associated pneumonia from randomized prevention studies. Crit Care Med 2011;39(12):2736-2742.

5. Kollef MH, Shorr A, Tabak YP, Gupta V, Liu LZ, Johannes RS. Epidemiology and outcomes of health-care-associated pneumonia: results from a large US database of culture-positive pneumonia. Chest 2005;128(6):3854-3862.

6. Nair GB, Niederman MS. Ventilator-associated pneumonia: present understanding and ongoing debates. Intensive Care Med 2015;41(1): 34-48.

7. Guillamet CV, Kollef MH. Update on ventilator-associated pneumonia. Curr Opin Crit Care 2015;21(5):430-438.

8. Graat ME, Choi G, Wolthuis EK, Korevaar JC, Spronk PE, Stoker $\mathrm{J}$, et al. The clinical value of daily routine chest radiographs in a mixed medical-surgical intensive care unit is low. Crit Care 2006; 10(1):R11.

9. Rea-Neto A, Youssef NC, Tuche F, Brunkhorst F, Ranieri VM, Reinhart K, Sakr Y. Diagnosis of ventilator-associated pneumonia: a systematic review of the literature. Crit Care 2008;12(2):R56.

10. Self WH, Courtney DM, McNaughton CD, Wunderink RG, Kline JA. High discordance of chest $\mathrm{x}$-ray and computed tomography for detection of pulmonary opacities in ED patients: implications for diagnosing pneumonia. Am J Emerg Med 2013;31(2):401405.

11. Nazerian P, Volpicelli G, Vanni S, Gigli C, Betti L, Bartolucci M, et al. Accuracy of lung ultrasound for the diagnosis of consolidations when compared to chest computed tomography. Am J Emerg Med 2015;33(5):620-625.

12. Lichtenstein DA, Mezière GA. Relevance of lung ultrasound in the diagnosis of acute respiratory failure: the BLUE protocol. Chest 2008;134(1):117-125.

13. Volpicelli G, Mussa A, Garofalo G, Cardinale L, Casoli G, Perotto $\mathrm{F}$, et al. Bedside lung ultrasound in the assessment of alveolarinterstitial syndrome. Am J Emerg Med 2006;24(6):689-696.

14. Christ-Crain M, Stolz D, Bingisser R, Müller C, Miedinger D, Huber $\mathrm{PR}$, et al. Procalcitonin guidance of antibiotic therapy in communityacquired pneumonia: a randomized trial. Am J Respir Crit Care Med 2006;174(1):84-93.

15. Christ-Crain M, Jaccard-Stolz D, Bingisser R, Gencay MM, Huber PR, Tamm M, Müller B. Effect of procalcitonin-guided treatment on antibiotic use and outcome in lower respiratory tract infections: cluster-randomised, single blinded intervention trial. Lancet 2004; 363(9409):600-607.

16. Schuetz P, Christ-Crain M, Wolbers M, Schild U, Thomann R, Falconnier C, et al.; ProHOSP Study Group. Effect of procalcitonin based guidelines compared to standard guidelines on antibiotic use in lower respiratory tract infections: the randomized-controlled multicenter ProHOSP Trial. JAMA 2009;302(10):1059-1066.

17. Gibot S, Cravoisy A, Levy B, Bene MC, Faure G, Bollaert PE. Soluble triggering receptor expressed on myeloid cells and the diagnosis of pneumonia. N Engl J Med 2004;350(5):451-458.
18. Zagli G, Cozzolino M, Terreni A, Biagioli T, Caldini AL, Peris A. Diagnosis of ventilator-associated pneumonia: a pilot, exploratory analysis of a new score based on procalcitonin and chest echography. Chest 2014;146(6):1578-1585.

19. Hanley JA, McNeil BJ. The meaning and use of the area under a receiver operating characteristic (ROC) curve. Radiology 1982; 143(1):29-36

20. Horan TC, Andrus M, Dudeck MA. CDC/NHSN surveillance definition of health care-associated infection and criteria for specific types of infections in the acute care setting. Am J Infect Control 2008;36(5):309-332.

21. Ego A, Preiser JC, Vincent JL. Impact of diagnostic criteria on the incidence of ventilator-associated pneumonia. Chest 2015;147(2): 347-355.

22. Hayden GE, Wrenn KW. Chest radiograph versus computed tomography scan in the evaluation for pneumonia. J Emerg Med 2009; 36(3):266-270.

23. Esayag Y, Nikitin I, Bar-Ziv J, Cytter R, Hadas-Halpern I, Zalut T, Yinnon AM. Diagnostic value of chest radiographs in bedridden patients suspected of having pneumonia. Am J Med 2010; 123(1):e1-e5.

24. Nseir S, Favory R, Jozefowicz E, Decamps F, Dewavrin F, Brunin G, et al.; VAT Study Group. Antimicrobial treatment for ventilatorassociated tracheobronchitis: a randomized, controlled, multicenter study. Crit Care 2008;12(3):R62.

25. Reissig A, Copetti R, Mathis G, Mempel C, Schuler A, Zechner P, et al. Lung ultrasound in the diagnosis and follow up of community acquired pneumonia: a prospective, multicenter, diagnostic accuracy study. Chest 2012;142(4):965-972.

26. Bourcier JE, Paquet J, Seinger M, Gallard E, Redonnet JP, Cheddadi F, et al. Performance comparison of lung ultrasound and chest X-ray for the diagnosis of pneumonia in the ED. Am J Emerg Med 2014; 32(2):115-118.

27. Shah VP, Tunik MG, Tsung JW. Prospective evaluation of point-ofcare ultrasonography for the diagnosis of pneumonia in children and young adults. JAMA Pediatr 2013;167(2):119-125.

28. Cortellaro F, Colombo S, Coen D, Duca PG. Lung ultrasound is an accurate diagnostic tool for the diagnosis of pneumonia in the emergency department. Emerg Med J 2012;29(1):19-23.

29. Mongodi S, Via G, Girard M, Rouquette I, Misset B, Braschi A, et al. Lung ultrasound for early diagnosis of ventilator-associated pneumonia. Chest 2016;149(4):969-980.

30. Berlet T, Etter R, Fehr T, Berger D, Sendi P, Merz TM. Sonographic patterns of lung consolidation in mechanically ventilated patients with and without ventilator-associated pneumonia: a prospective cohort study. J Crit Care 2015;30(2):327-333.

31. Lichtenstein DA, Lascols N, Mezière G, Gepner A. Ultrasound diagnosis of alveolar consolidation in the critically ill. Intensive Care Med 2004;30(2):276-281.

32. Wang G, Ji X, Xu Y, Xiang X. Lung ultrasound: a promising tool to monitor ventilator-associated pneumonia in critically ill patients. Crit Care 2016;20(1):320

33. Bouhemad B, Liu ZH, Arbelot C, Zhang M, Ferarri F, Le-Guen M, et al. Ultrasound assessment of antibiotic-induced pulmonary reaeration in ventilator-associated pneumonia. Crit Care Med 2010;38(1): 84-92.

34. Christ-Crain M, Opal SM. Clinical review: the role of biomarkers in the diagnosis and management of community-acquired pneumonia. Crit Care 2010;14(1):203.

35. Luyt CE, Combes A, Trouillet JL, Chastre J. Value of the serum procalcitonin level to guide antimicrobial therapy for patients with ventilator-associated pneumonia. Semin Respir Crit Care Med 2011; 32(2):181-187. 


\section{LUNG UltRASOUND FOR VAP DiAgNOSIS}

36. Luyt CE, Combes A, Reynaud C, Hekimian G, Nieszkowska A, Tonnellier M, et al. Usefulness of procalcitonin for the diagnosis of ventilator-associated pneumonia. Intensive Care Med 2008;34(8): 1434-1440.

37. Jung B, Embriaco N, Roux F, Forel JM, Demory D, Allardet-Servent $\mathrm{J}$, et al. Microbiological data, but not procalcitonin improve the accuracy of the clinical pulmonary infection score. Intensive Care Med 2010;36(5):790-798.

38. Wahidi MM, Rocha AT, Hollingsworth JW, Govert JA, FellerKopman D, Ernst A. Contraindications and safety of transbronchial lung biopsy via flexible bronchoscopy. Respiration 2005; 72(3):285-295.

This article is approved for Continuing Respiratory Care Education credit. For information and to obtain your CRCE

(free to AARC members) visit

www.rcjournal.com 